Nevşehir Bilim ve Teknoloji Dergisi Cilt 6(1) 63-78 2017

DOI: 10.17100/nevbiltek.288003

URL: http://dx.doi.org/10.17100/nevbiltek.288003

\title{
Analitik Hiyerarşi Proses ve Bulanık Analitik Hiyerarşi Proses Yöntemleri Kullanılarak Yeşil Tedarikçi Seçimi Uygulaması
}

\author{
Berrin DENIZZHAN $^{1, *}$, Ayten YILMAZ YALÇINER ${ }^{1}$, Şafak BERBER ${ }^{2}$ \\ ${ }^{1}$ Sakarya Üniversitesi, Mühendislik Fakültesi, Endüstri Mühendisliği Bölümü, Sakarya \\ ${ }^{2}$ Birleşik Yazılım Hizmetleri Ltd. Şti. Yıldız Teknik Üniversitesi Teknoloji Geliştirme Bölgesi İstanbul
}

Öz

Tedarikçi ilişkilerinde tedarikçi seçim kararı bir işletmenin en önemli başarı faktörlerinden biridir. Bu çalışmanın amacı yeşil tedarikçi seçiminin klasik tedarikçi seçimi ile olan farklılığını ve önemini ortaya koymaktır. Doğu Marmara bölgesinde makina imalatı sektöründe yer alan firmaların tedarikçi seçimi incelenmiştir. Anket yöntemi ile yeşil tedarikçi seçim kriterleri belirlenmiş ve önerilen kriterlerle yeşil tedarikçi seçimi AHP ve Bulanık AHP yöntemleri kullanılarak belirlenmiştir. Klasik tedarikçi seçim kriterleri ile de tedarikçi seçimi yapılmıştır. Yeşil kriterle elde edilen sonuç klasik kriterler ile yapılan tedarikçi seçiminden farklı olmuştur. Bu çalışma firmalar tarafindan seçim yöntemlerinin kullanılabilirliğini ve sektör için yeşil kriterlerin belirlenmesine katkıda bulunmaktadır.

Anahtar Kelimeler: Analitik hiyerarşi proses (AHP), Bulanık AHP, Yeşil tedarikçi seçimi, Yeşil tedarikçi ilişkileri

\section{An Application of Green Supplier Selection Using Analytic Hierarchy Process and Fuzzy Analytic Hierarchy Process Methods}

\begin{abstract}
Supplier selection decision is one of the key success factors in supplier relations. The aim of this study is to compare the performance of two popular multi criteria decision making methods which are AHP and Fuzzy AHP on green supplier selection case. Also it shows how green supplier selection criteria effect on supplier selection decision. The supplier selection of firms in the machinery manufacturing sector in the Eastern Marmara region has been examined. The green supplier selection criteria were determined by the survey method and the green supplier selection by the recommended criteria was determined by using AHP and Fuzzy AHP methods. The supplier selection was made with the classic supplier selection criteria as well. The results obtained with the green criterion were different from the supplier selection made with the classical criteria. This study also provided us with the applicability of selection methods and the determination of green criteria for the sector.
\end{abstract}

Keywords: Analytic hierarchy process (AHP), Fuzzy AHP, Green Supplier Selection, Green Supplier Relations

* e-mail: denizhan@sakarya.edu.tr 


\section{Giriş}

Tedarikçi seçimi, sorunun/İhtiyaçların tanımlanması, kriterlerin oluşturulması, potansiyel tedarikçilerin belirlenmesi ve son seçim aşamasından oluşan bir süreçtir. Yeşil tedarik zinciri ile birlikte yaygın olan kriterlerin yanı sıra çevresel kriterlerin de değerlendirilmesini gerektirmektedir $[3,4,13]$. Geçmişte tedarikçi seçimi için tanımlanan kriterler normal olarak, fiyat rekabeti üzerine odaklanırken, yeşil uygulamalarda işletmeler, ürün, üretim, ekonomik kârlılık ve sürdürülebilirliği sağlamak için en önemli kriter olarak ekolojik koşulları öncelikli değerlendirmek zorundadır. Yeşil tedarik zinciri ile geleneksel tedarik zinciri arasındaki farkı tablo 1. de görüldüğü gibi maliyet ve tedarik zinciri ilişkilerine yansımaktadır $[7,5]$.

Tablo 1. Geleneksel Tedarik Zinciri Yönetimi ve Yeşil Tedarik Zinciri Yönetimi Fark1

\begin{tabular}{ccc}
\hline Özellikler & Geleneksel Tedarik Zinciri Yönetimi & Yeşil Tedarik Zinciri Yönetimi \\
Amaç ve değerler & Ekonomik & Ekonomik ve ekolojik \\
Ekolojik optimizasyon & Yüksek entegre yaklaşım & Ekolojik etkiler \\
Tedarikçi seçimi kriterleri & Fiyat değiştirme & Ekonomik görünüm \\
Maliyet fiyatları & Kisa vadeli tedarikçi ilişkileri & Uzun süreli tedarikçi ilişkileri \\
Hız ve esneklik & Düşük & Yüksek \\
\hline
\end{tabular}

Yeşil tedarikçi seçiminde önem kazanan ilk kriter tasarım kriterleridir. Daha sonra imalat sürecini ilgilendiren tüm alanlarda yeşil kriterler oluşmaktadır. Üretim kriterleri; Üretimde kullanılan, tehlikeli madde miktarını en aza indirme, su ve enerjiyi azaltmak için önlemler alma, doğal kaynakları en aza indirme ve üretimde oluşan zehirli atıkların azaltılması olarak sayılabilir. Teknoloji kriterlerinden bazıları ise; Ar-Ge teknoloji düzeyi yeteneği, temiz teknoloji, teknik uzmanlıktır. Yeşil lojistik kriterlerinden bazıları; Sürdürülebilir ulaşım/taşımacılık, tehlikeli madde depolama, envanter seviyesi, depolama, paketleme ve tesis kontrolüdür. Yeşil tasarım becerisi, tehlikeli madde envanteri, yasal uyum yetkinliği ise süreç, çevre ve Ar-ge yönetimi kriterlerinden bazılarıdır [5, 9, 1].

Yapılan literatür araştırmalarında 2000 yılından önce yeşil tedarikçi seçimi problemi ile ilgili sadece iki adet yayın varken 2000 yılından sonra bu sayı artarak 2007 yılında yediye ulaşmış ve artmaya devam etmiştir. Dolayısı ile hala güncelliğini koruyan ve araştırma ve uygulamaya açık bir alan olduğu gözlemlenmektedir [1]. Tedarikçi seçme problemi karar aşamasında birçok kriterin dikkate alınmasını gerektiren karmaşık bir karar problemi olup, sezgisel ve analitik karar yaklaşımlar ile çözüme ulaşılabilir $[14,16]$. Klasik tedarikçi seçimi problemlerinde yaygın olarak kullanılan yöntem ve yaklaşımlar yeşil tedarikçi seçiminde de kullanılmaktadır. Önemli olan unsur yeşil kriterlerin işletmeye uygun, ekonomik ve yasalara uygun olarak belirlenmesidir [1, 2, 14]. Güner'in 2010 y1lında gerçekleştirdiği bir çalışmasında, KOBİ’lerde yeşil tedarik zinciri algılaması araştırılmıştır. Tedarikçi seçiminde önem verilen faktörlerin önem sırasına göre sıralanmasında katılımcılar sırasıyla fiyat, kalite, zamanında teslim, servis kalitesi, sertifikalar ve coğrafi konum faktörlerinin ardında çok küçük bir oranla yeşil tedarik zinciri algısı görülmüştür[8]. Başka bir çalışmada ise yöneticilerin yeşil tedarikçi seçim kriterleri listesini oluşturulmuştur.[14]. Tedarikçi seçim problemlerinde yaygın yöntemler olarak; Analitik Hiyerarşi Prosesi (AHP), Analitik Network Prosesi (ANP), Veri Zarflama Yöntemi, Bulanık Küme Teorisi, Matematiksel Programlama, SMART, ELECTRE, TOPSIS, PROMETHEE ve bu yöntemlerin 
entegrasyonu gibi çok kriterli karar verme yaklaşımları da kullanılmaktadır [10, 14, 15, 18, 21, 22]. Nihai seçim için karar yöntemleri ise doğrusal model, matematiksel programlama modelleri, istatistiksel modeller, yapay zekâ tabanlı modeller olmak üzere sinıflandırılmaktadır [1, 4, 22].

$\mathrm{Bu}$ çalışmanın amacı yeşil kriterler göz önüne alındığında tedarikçi seçimi sonucunun nasıl etkilendiğini göstermektir. Aynı zamanda gittikçe zorunluluk haline gelen yeşil üretime uyum süreçlerindeki, tedarikçi seçiminde, yeşil kriterlerin uygulanabilirliğini de görülmektedir. Yeşil kriterlerin belirlenmesi önemli unsurlardan biridir. Bu çalışmadaki kriterler ise Doğu Marmara bölgesinde yer alan 12 ana üretici firma ile yüzyüze görüşme ve anket uygulaması ile oluşturulmuştur. Hedef tanımı yapıldıktan sonra, kriterler değerlendirilmiş ve en uygun olanlar değerlendirme hedefleri kullanılarak seçilmiştir. Tedarikçi seçim problemlerinde kriterlerin belirlenmesinin ve sınıflandırılmasının ardından, işletme için en uygun seçim modelinin seçilmesi de önemlidir. Katılımcı firmalar ile oluşturulan yeşil kriterler analitik hiyerarşi proses (AHP) Bulanık AHP yöntemleri kullanılarak kıyaslanmıştır.

\section{Analitik Hiyerarşi Prosesi(AHP) Yöntemi}

Analitik Hiyerarşi Prosesi (AHP), 1977 yllında Thomas L. Saaty (1980) tarafindan geliştirilen geniş bir alanda kullanılan çok amaçlı karar verme metotlarından biridir [17]. Çoklu hiyerarşik yapıya sahip amaç, kriter ve alternatif problemlerinin ayrıştııılmasında karar vericiye yardımcı olur. Hiyerarşik yapıda alt kriterlerin bulunduğu problemlerin çözümüne uygundur [6, 17].

AHP dört asamadan oluşmaktadır. Karar verme aşaması, problemi tanımlama ve ayrıştırma olarak da bilinir. Öncelikle, karar verme probleminin daha kolay kavranmasını ve değerlendirilmesini sağlayacak hiyerarşik bir düzende alt problemlere ayrıştırılır. Önce çalışmanın amacı belirlenir, sonra bu amaca uygun kriterler belirlenir. Konuyla ilgili birden fazla kriter belirlenebileceği gibi bu kriterlerin alt kriterleri de olabilir. Karar hiyerarşisinin en tepesinde ana hedef yer almaktadır. Bir kriterlerin, ana hedefi etkileyebilecek özellikleri varsa, hiyerarşiye başka alt hedefler eklenebilir. Hiyerarşinin en altında karar alternatifleri yer almaktadır [11, 17]. AHP'nin ikinci adımı ikili karşılaştımalardır. İkili karsılaştırma kriterlerin birbiriyle karsılaştırması anlamına gelir ve karar vericinin yargısına dayanır. İkili karşılaştırmalar sonucunda herbir kriterin ağırlıkları belirlenir [21, 17]. Farklı kriterlerin Tablo 2.'de gösterildiği gibi ikili karsılaştırmaları yapılarak bir matris oluşturulur. Matristeki $W_{i} / W_{j}$ terimi, amaca ulaşmak için $i$. kriterin, $j$. kriterden ne kadar daha önemli olduğunu ifade etmektedir. Bu değerlendirmede Tablo 3 'de gösterilen ölçek kullanılmaktadır. Örneğin bu değer 5 ise, $i$. kriterin $j$. kritere göre kuvvetli düzeyde önemli olduğu anlaşılmaktadır. Bu durumda benzer sekil $j$. kriter de $i$. kritere göre $1 / 5$ düzeyinde önemli olmaktadır. Bu matrisin köşegeni üzerindeki matris bileşenleri 1 değerini alır ( $i=j)$ [15].

Tablo 2. Kriterler için İkili Karşılaş̧ırma Matrisi Oluşturulması [20].

\begin{tabular}{llll}
\hline & Kriter 1 & Kriter 2 & Kriter $\boldsymbol{j}$ \\
Kriter 1 & $W_{1} / W_{1}$ & $W_{1} / W_{2}$ & $W_{1} / W_{j}$ \\
Kriter 2 & $W_{2} / W_{1}$ & $W_{2} / W_{2}$ & $W_{2} / W_{j}$ \\
Kriter $\boldsymbol{i}$ & $W_{i} / W_{1}$ & $W_{i} / W_{2}$ & $W_{i} / W_{j}$ \\
\hline
\end{tabular}

İkili karşılaştırma, eşit önem derecesinin göstergesi olan 1'den, aşırı düzeyde önem derecesi olan 9'a kadar değişen ölçeğe göre yapılmaktadır. Örneğin bu değer 9 ise, $i$. kriterin $j$. kritere göre aşırı 
düzeyde önemli olduğu anlaşılmaktadır. Bu durumda benzer sekil $j$. kriter de $i$. Kritere göre 1/9 düzeyinde önemli olmaktadır.

Tablo 3. Analitik Hiyerarşi Sürecinde Kullanılan Ölçek[17]

\begin{tabular}{|c|c|c|}
\hline $\begin{array}{l}\text { Önem } \\
\text { Derecesi }\end{array}$ & Tanım & Açıklama \\
\hline 1 & Eşit önem & $\begin{array}{l}\text { İki faaliyet amaca eşit düzeyde katkıda } \\
\text { bulunuyor }\end{array}$ \\
\hline 3 & $\begin{array}{l}\text { Birinin diğerine göre orta } \\
\text { derecede daha önemli olması }\end{array}$ & $\begin{array}{l}\text { Tecrübe ve yargı faaliyeti diğerine orta } \\
\text { derecede tercih ettiriyor }\end{array}$ \\
\hline 5 & Kuvvetli düzeyde önem & $\begin{array}{c}\text { Tecrübe ve yargı faaliyeti diğerine kuvvetli bir şekilde tercih } \\
\text { ettiriyor }\end{array}$ \\
\hline 7 & Çok kuvvetli düzeyde önem & $\begin{array}{c}\text { Bir faaliyet güçlü bir şekilde tercih ediliyor ve baskınlığı } \\
\text { uygulamada rahatla görülür }\end{array}$ \\
\hline 9 & Aşırı düzeyde önem & $\begin{array}{l}\text { Bir faaliyetin diğerine tercih edilmesine } \\
\text { ilişkin kanıtlar büyük bir güvenliğe sahip }\end{array}$ \\
\hline $2,4,6,8$ & Ortalama değerler & $\begin{array}{c}\text { Uzlaşma gerektiğinde kullanmak üzere iki ardışık yargı } \\
\text { arasına düşen değerdir }\end{array}$ \\
\hline
\end{tabular}

Üçüncü sentez aşamasında karşılaştırılan her elemanın göreli önceliğinin hesaplanır. Öncelik vektörlerinin kurulmasında, lineer cebir tekniklerinden faydalanılmaktadır. Sentez aşaması, en büyük özdeğer ve bu özdeğere karşılık gelen özvektörün hesaplanmasını ve normalize edilmesini içermektedir. Literatürde yaygın olarak kullanılan normalizasyon yönteminde, her sütunun elemanları, o sütunun toplamına bölünür. Elde edilen değerlerin satır toplamı, bu toplam satırdaki eleman sayısına bölünür. Bu yöntem ile her bir ölçüt için, öncelik vektörleri bulunur. En son aşamada, nihai kararların tutarlılığının kontrol edilir. Tutarlı olmak bir önkoşul olarak kabul edilir. Ancak uygulamada tam anlamıyla tutarlılık neredeyse imkânsızdır. AHP mükemmel derecede tutarlılık talep etmemektedir. Tutarsızlığa izin vermekte ancak her yargılamada tutarsızlığın ölçümünü sağlamaktadır. İkili karsılaştırmaların tutarlılığını ölçmek için Saaty tarafından önerilen tutarlılık oranı kullanılmaktadır [17].

\section{Bulanık Analitik Hiyerarşi Prosesi (BAHP) Yöntemi}

Bulanık küme teorisi ilk olarak Lotfi Zadeh tarafından 1965 yılında çalışılmıştır. Zadeh, bulanık kümeler kavramında üyelik derecesinin 0 ile 1 arasında değişebileceğini ileriye sürerek kümeler teorisinde geniş uygulamaya sahip ve doğal hayatta uyumlu olan bulanık küme teorisini geliştirmiştir [19, 23]. Bulanık küme mantığında küme aitlik derecesi $(\mu)$ ile gösterilir ve 0 ile 1 arasında değer alır. " 0 " değeri kesin olarak kümeye ait olmamayı gösterirken, "1” değeri ise kesin olarak kümeye ait olmayı yani üyeliği ifade eder.

AHP yöntemi ise sık kullanılan çok kriterli yaklaşımlardan biridir. Ancak karar vericilerin düşüncelerini ele almada tam değerlerin kullanılması ve ikili karşılaştırma sürecindeki belirsizlik ve dikkatsizlikleri ele almadaki yetersizliğinden dolayı eleştirilmektedir [Kargın, 2010]. Bu sebeple birçok karar verme problemindeki en önemli sorunlardan biri bulanıklığın olmasıdır. Eğer çözülmesi istenen problemde belirsizlik varsa, bu belirsizliğin tolere edilebilmesi gerekir. Çeşitli problem tiplerini çözmek için birçok Bulanık AHP metodu kullanılmaktadır. Bunlar; 
1. Genişletilmiş (Chang’in) Analiz Yöntemi(1996)

2. Liou ve Wang'ın Yöntemi (1992)

3. Abdel-Kader ve Yöntemi (2001)

$\mathrm{Bu}$ çalışmada Chang (1996) tarafından önerilen Genişletilmiş Analiz Yöntemi kullanılmıştır. Çünkü bu yöntem farklı BAHP yöntemlerine göre adımları daha kolay, daha az zaman ve hesaplama gerektirmektedir. Ayrıca geleneksel AHP eksikliklerini de kapatabilir [12]. Chang'in yaklaşımına göre ikili karşılaştırmalar üçgensel bulanık sayılarla temsil edilmektedir. Bulanık sayıların kullanılması ile tahminden kaynaklanan dezavantajlar giderilmeye çalışılmıştır. Chang’in yöntemine göre, her bir ölçüt alınır ve her bir hedef için mertebe analizi uygulanır. Böylece her bir ölçüt için $m$ tane mertebe analiz değerleri elde edilir. Bu değerler şu şekilde gösterilir.

$$
M_{g_{i}}^{1}, M_{g_{i}}^{2}, \ldots \ldots \ldots \ldots, M_{g_{i}}^{m} \quad i=1,2, \ldots \ldots, n
$$

Burada tüm $M_{g_{i}}^{J}(j=1,2, \ldots \ldots, n)$ 'ler üçgensel bulanık sayılardır. Bu sayılar tablo 4' de görülmektedir. Chang’in analizinin adımları ise şu şekilde özetlenebilir.

Adım 1: Ölçüt $i$ ’ ye göre bulanık sentetik mertebenin değeri şu şekilde tanımlanır.

$$
S_{i}=\sum_{j=1}^{m} M_{g_{i}}^{j} *\left[\sum_{i=1}^{n} \sum_{j=1}^{m} M_{g_{i}}^{j}\right]^{-1}
$$

$S_{i}=i$. Amacın sentez değeri $M_{g_{i}}^{j}=$ her bir amaca yönelik genişletilmiş değerdir.

Birinci aşamanın sonunda aşağıdaki ifade hesaplanır.

$$
\left[\sum_{i=1}^{n} \sum_{j=1}^{m} M_{g_{i}}^{j}\right]^{-1}=\left[\frac{1}{\sum_{i=1}^{n} u_{i}}, \frac{1}{\sum_{i=1}^{n} m_{i}}, \frac{1}{\sum_{i=1}^{n} l_{i}}\right]
$$

Adım 2: $M_{2}=\left(l_{2}, m_{2}, u_{2}\right) \geq M_{1}=\left(l_{1}, m_{1}, u_{1}\right)$ ifadesinin olabilirlik derecesi söyle tanımlanır:

$$
V(M 2 \geq M 1)=\mid \begin{array}{cc}
1 & m_{2} \geq m_{1} \\
0 & l_{1} \geq u_{2} \\
\frac{l_{1}-u_{2}}{\left(m_{2}-u_{2}\right)-\left(m_{1}\right.} & \text { diğer } \\
\left.-l_{1}\right) &
\end{array}
$$

Burada karşılaştırılan iki durum için kesişim noktası bulunuyor. $M_{1}$ ve $M_{2}$ 'yi kıyaslayabilmek için $\mathrm{V}\left(\mathrm{M}_{2}\right.$ $\left.\geq \mathrm{M}_{1}\right)$ ve $V(M 1 \geq M 2)$ değerlerinin her ikisi de gerekmektedir.

Adım 3: 1. satır diğer tüm satırlarla karşılaştırılır. Bu karşılaştırmalar sonucunda çıkan değerlerin minimumu alınır(d' $\left.\left(A_{1}\right)\right)$. Aynı şekilde 2. satırda diğer tüm satırlarla karşılaştırılır ve minimumu alınır $\left(d^{\prime}\left(A_{2}\right)\right)$. Bu işlem tüm satırlar için devam ettirilir. Her satır için bulunan minimum değerler birleştirilerek ağırlık vektörü elde edilir. 
$W^{\prime}=\left(d^{\prime}\left(A_{1}\right), d^{\prime}\left(A_{2}\right), \ldots, d^{\prime}\left(A_{n}\right)\right)^{T}$

Adım 4: Ağırlık vektörü normalize edilir. Burada $W$, bulanık olmayan bir sayıdır.

Tablo 4. Bulanık Sayılar

\begin{tabular}{|c|c|c|}
\hline & Üçensel Bulanık Sayı & $\begin{array}{c}\text { Üçgensel Bulanık Sayıların } \\
\text { Tersi }\end{array}$ \\
\hline 1 & $(1,1,2)$ & $(1 / 2,1,1)$ \\
\hline 2 & $(1,2,3)$ & $(1 / 3,1 / 2,1)$ \\
\hline 3 & $(2,3,4)$ & $(1 / 4,1 / 3,1 / 2)$ \\
\hline 4 & $(3,4,5)$ & $(1 / 5,1 / 4,1 / 3)$ \\
\hline 5 & $(4,5,6)$ & $(1 / 6,1 / 5,1 / 4)$ \\
\hline 6 & $(5,6,7)$ & $(1 / 7,1 / 6,1 / 5)$ \\
\hline 7 & $(6,7,8)$ & $(1 / 8,1 / 7,1 / 6)$ \\
\hline 8 & $(7,8,9)$ & $(1 / 9,1 / 8,1 / 7)$ \\
\hline 9 & $(8,9,9)$ & $(1 / 9,1 / 9,1 / 8)$ \\
\hline
\end{tabular}

4. Uygulama: AHP ve Bulanık AHP Yöntemleri Kullanılarak Makina İmalatı Sektöründe Yeşil Tedarikçi Seçimi Uygulaması

$\mathrm{Bu}$ çalışmada; uygulama öncesi firmaların yeşil tedarikçi bilicini, tedarikçi seçme kriterlerini ve kriterlerin önceliklerini belirlemek için, çeşitli sektörlerden on firma üzerinde bir anket çalışması yapılmıştır. Daha sonra elde edilen anket sonuçlarına dayanarak yeşil tedarikçi seçimi kriterleri belirlenmiştir. Bu yeni kriterler de ilave edilerek AHP ve Bulanık AHP yöntemleri ile Makine İmalatı Sektöründe Yeşil Tedarikçi Seçimine dair örnek bir uygulama yapılmıştır. Anket sonuçları doğrultusunda; en uygun ve en yeşil tedarikçiyi seçmek için ön plana çıkan kriterler ve öncelikleri belirlenerek, üç tedarikçi firma üzerinde değerlendirme yapılmıştır. Aşağıda verilen şekil 1. de; amaç, kriterler ve seçenekler bir arada gösterilmektedir.

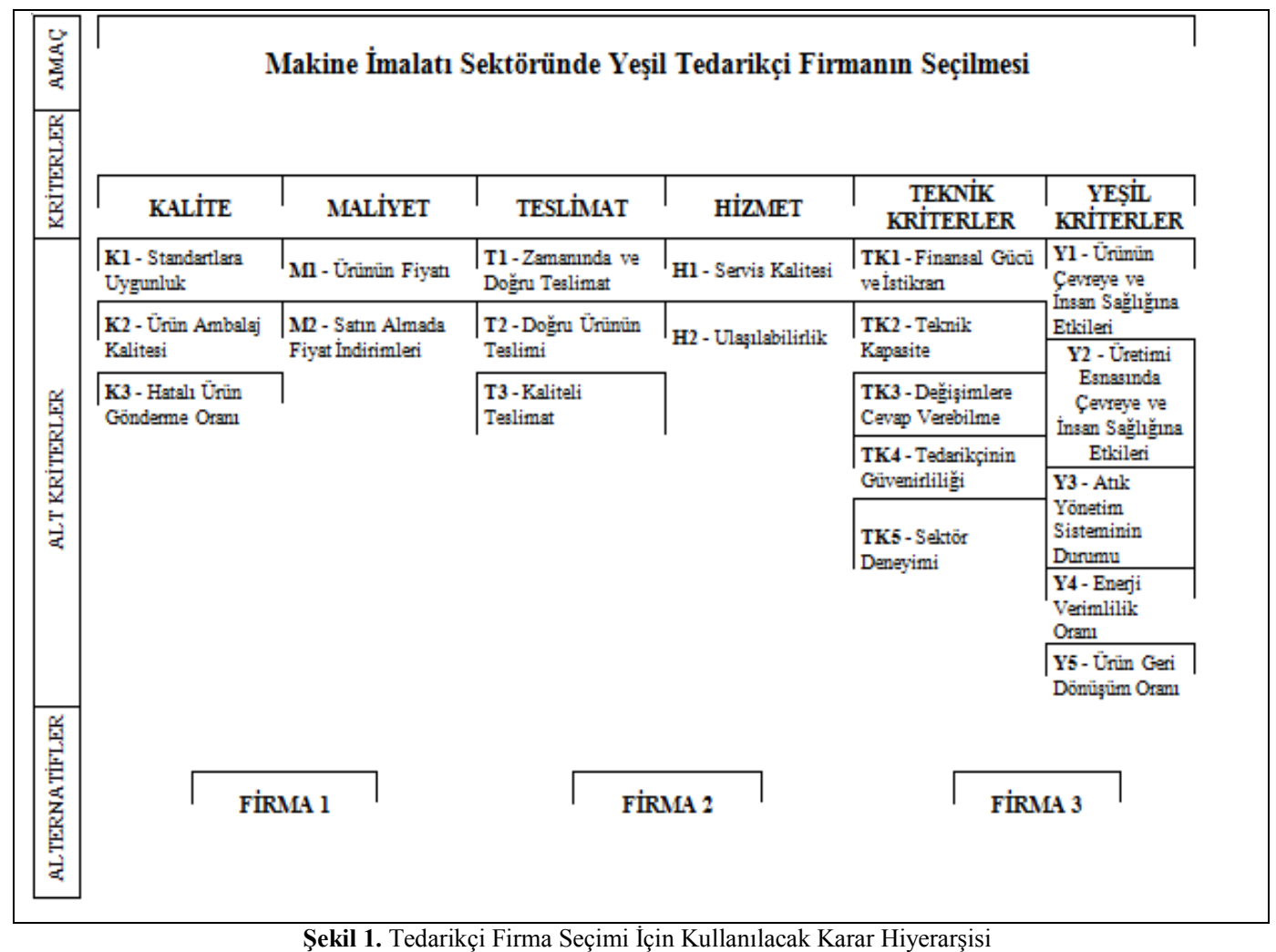

Şekil 1. Tedarikçi Firma Seçimi İçin Kullanılacak Karar Hiyerarşisi 


\subsection{AHP Yöntemi ile En Uygun Tedarikçinin Seçimi}

AHP yöntemi ile yeşil kriterler dâhil edilmeden en uygun tedarikçi ve yeşil kriterler dâhil edilerek en uygun yeşil tedarikçi belirlenmiştir. Çözümler Expert Choice programı kullanılarak yapılmıştır. En uygun tedarikçiyi belirleyebilmek için ana kriterler karşılaştırılarak öncelik matrisi oluşturulur. Tablo 5' de ikili karşılaştırmalar matrisi, tablo 6 ve tablo 7 da ise kalite ve teslimat kriterlerinin karşılaştırma matrisleri görülmektedir. Diğer kriterler için de karşılaştırma matrisi oluşturulmuştur.

Tablo 5. Ana Kriterlerin İkili Karșılaștırma Matrisi

\begin{tabular}{|c|c|c|c|c|c|}
\hline & KALITTE & MALIYET & TESLIMAT & HIZMET & $\begin{array}{c}\text { TEKNIK } \\
\text { KRİTERLER }\end{array}$ \\
\hline KALITE & 1 & 7 & 2 & 5 & 3 \\
\hline MALIYET & $1 / 7$ & 1 & $1 / 5$ & $1 / 3$ & $1 / 5$ \\
\hline TESLIMAT & $1 / 2$ & 5 & 1 & 3 & 2 \\
\hline HIZZMET & $1 / 5$ & 3 & $1 / 3$ & 1 & $1 / 3$ \\
\hline TEKNIK KRITERLER & $1 / 3$ & 5 & $1 / 2$ & 3 & 1 \\
\hline
\end{tabular}

Her bir ana kritere ait alt kriterlerin öncelik matrisleri oluşturularak çözüme devam edilir.

\begin{tabular}{cccc}
\multicolumn{4}{c}{ Tablo 6. Kalite Kriterlerinin Karş. } \\
\hline KALíTE & K1 & K2 & K3 \\
K1 & 1 & 3 & 2 \\
K2 & $1 / 3$ & 1 & $1 / 2$ \\
K3 & $1 / 2$ & 2 & 1 \\
\hline
\end{tabular}

\begin{tabular}{cccc}
\multicolumn{4}{c}{ Tablo 7.Teslimat Kriterlerinin Karş. } \\
\hline TESLIMAT & T1 & T2 & T3 \\
T1 & 1 & 3 & 5 \\
T2 & $1 / 3$ & 1 & 3 \\
T3 & $1 / 5$ & $1 / 3$ & 1 \\
\hline
\end{tabular}

Tüm kriterlerin öncelikleri belirlendikten sonra bu değerler Expert Choice programına girilerek kriterlerin ağırlıkları elde edilir. Tüm kriterlere göre, tablo 8 ve tablo 9 da olduğu gibi, her bir firma değerlendirilerek çözüme devam edilir.

\begin{tabular}{cccc}
\multicolumn{5}{c}{ Tablo 8. K1 için firmaların karş. } \\
\hline K1 & FİRMA 1 & FíRMA 2 & FİRMA 3 \\
FIRMA 1 & 1 & 2 & 3 \\
FIRMA 2 & $1 / 2$ & 1 & 2 \\
FIRMA 3 & $1 / 3$ & $1 / 2$ & 1 \\
\hline
\end{tabular}

\begin{tabular}{cccc}
\multicolumn{5}{c}{ Tablo 9. K2 için firmaların karş. } \\
\hline K2 & FİRMA 1 & FİRMA 2 & FÍRMA 3 \\
FİRMA 1 & 1 & $1 / 2$ & 2 \\
FíRMA 2 & 2 & 1 & 5 \\
FİRMA 3 & $1 / 2$ & $1 / 5$ & 1 \\
\hline
\end{tabular}

Firma değerlendirme sonuçlarını Expert Choice programına girerek en uygun tedarikçi belirlenmiştir. 
Şekil 2. AHP ile Tedarikçi Seçimi Sonuçları

Şekil 2 de görüldüğü gibi, AHP yöntemi ile \%2 tutarlılık oranı ile elde edilen sonuca göre; \%42,8 oran ile Firma 2, en uygun tedarikçi seçilmiştir.

\subsection{AHP Yöntemi ile Yeşil Kriterlere Göre En Uygun Tedarikçinin Seçimi}

En uygun yeşil tedarikçiyi belirleyebilmek için yeşil kriterlerin eklendiği tablo 10 da yer alan ana kriterler karşılaştırılarak öncelik matrisi oluşturulur.

Tablo 10. Ana Kriterlerin İkili Karşılaştırma Matrisi

\begin{tabular}{|c|c|c|c|c|c|c|}
\hline & KALİTE & MALIYET & TESLIMMAT & HİZMET & $\begin{array}{c}\text { TEKNIK } \\
\text { KRITTERLER }\end{array}$ & $\begin{array}{c}\text { YEŞiL } \\
\text { KRITTERLER }\end{array}$ \\
\hline KALİTE & 1 & 7 & 2 & 5 & 3 & 1 \\
\hline MALIYET & $1 / 7$ & 1 & $1 / 5$ & $1 / 3$ & $1 / 5$ & $1 / 9$ \\
\hline TESLİMAT & $1 / 2$ & 5 & 1 & 3 & 2 & $1 / 3$ \\
\hline HİZMET & $1 / 5$ & 3 & $1 / 3$ & 1 & $1 / 3$ & $1 / 7$ \\
\hline $\begin{array}{c}\text { TEKNIK } \\
\text { KRITTERLER }\end{array}$ & $1 / 3$ & 5 & $1 / 2$ & 3 & 1 & $1 / 5$ \\
\hline $\begin{array}{c}\text { YEŞILL } \\
\text { KRİTERLER }\end{array}$ & 1 & 9 & 3 & 7 & 5 & 1 \\
\hline
\end{tabular}

Yeşil kriterler dışındaki alt kriterlerin öncelik ve tedarikçi değerlendirme matrisleri, bir önceki çözümde belirtildiği gibidir. Yeşil kriterlerin öncelik ve tedarikçi değerlendirme matrisleri aşağıda, tablo 11 de verilmiştir.

\begin{tabular}{cccccc}
\multicolumn{7}{c}{ Tablo 11. Yeşil Kriterlerin Karşılaştırılmasi } \\
\hline Yeșil kriterler & Y1 & Y2 & Y3 & Y4 & Y5 \\
Y1 & 1 & 1 & 5 & 3 & 7 \\
Y2 & 1 & 1 & 3 & 3 & 7 \\
Y3 & $1 / 5$ & $1 / 3$ & 1 & $1 / 3$ & 3 \\
Y4 & $1 / 3$ & $1 / 3$ & 3 & 1 & 3 \\
Y5 & $1 / 7$ & $1 / 7$ & $1 / 3$ & $1 / 3$ & 1 \\
\hline
\end{tabular}

Tüm kriterlerin öncelikleri belirlendikten sonra bu değerler Expert Choice programına girilerek kriterlerin ağırlıkları elde edilir. Tüm kriterlere göre her bir firma değerlendirilerek çözüme devam edilir. Yeşil kriterler dışındaki kriterlerin firmalara göre değerlendirilme matrisleri, bir önceki çözümde 
verilmiştir. Yeşil kriterler de firmalara göre değerlendirilerek çözüme devam edilir. Firma değerlendirme sonuçlarını Expert Choice programına girerek en uygun yeşil tedarikçi belirlenmiştir.

Synthesis with respect to: Goal: YEŞiL TEDARIKÇi SEÇimi

Overall Inconsistency $=, 04$

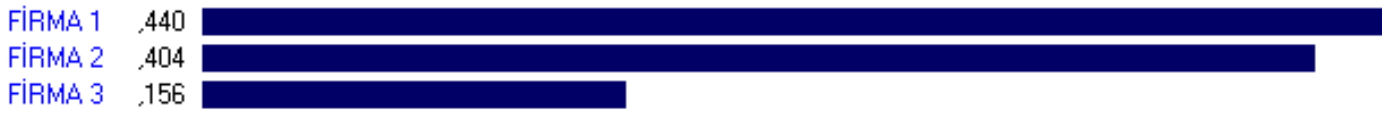

Şekil 3. AHP ile Yeşil Tedarikçi Seçimi Sonuçları

Şekil 3 de görüldüğü gibi \%4 tutarlılık oranı ile elde edilen sonuca göre; \%44 oran ile Firma 1, AHP yöntemi ile en uygun yeşil tedarikçi seçilmiştir.

\subsection{Bulanık AHP Yöntemi ile En Uygun Tedarikçinin Seçimi}

Bulanık AHP yöntemi ile yeşil kriterler dâhil edilmeden en uygun tedarikçi ve yeşil kriterler dâhil edilerek en uygun yeşil tedarikçi belirlenecektir. Çözümler Excel yardımıyla yapılacaktır. En uygun tedarikçiyi belirleyebilmek için ana kriterler karşılaştırılarak tablo 12 de yer alan öncelik matrisi oluşturulur.

Tablo 12. Ana Kriterlerin Bulanık İkili Karşılaştırma Matrisi

\begin{tabular}{|c|c|c|c|c|c|c|c|c|c|c|c|c|c|c|c|}
\hline \multicolumn{16}{|c|}{ Makina İmalatı Sektöründe Tedarikçi Seçimi } \\
\hline \multirow[b]{3}{*}{ KALİTE } & l & $\mathrm{m}$ & $\mathrm{u}$ & l & $\mathrm{m}$ & $\mathrm{u}$ & 1 & $\mathrm{~m}$ & $\mathrm{u}$ & 1 & $\mathrm{~m}$ & $\mathrm{u}$ & 1 & $\mathrm{~m}$ & $\mathrm{u}$ \\
\hline & \multicolumn{3}{|c|}{ KALITE } & \multicolumn{3}{|c|}{ MALIYYT } & \multicolumn{3}{|c|}{ TESLIMAT } & \multicolumn{3}{|c|}{ HIZMET } & \multicolumn{3}{|c|}{ TEKNIKK K. } \\
\hline & 1 & 1 & 1 & 6 & 7 & 8 & 1 & 2 & 3 & 4 & 5 & 6 & 2 & 3 & 4 \\
\hline MALIYYT & $1 / 8$ & $1 / 7$ & $1 / 6$ & 1 & 1 & 1 & $1 / 6$ & $1 / 5$ & $1 / 4$ & $1 / 4$ & $1 / 3$ & $1 / 2$ & $1 / 6$ & $1 / 5$ & $1 / 4$ \\
\hline TESLIMAT & $1 / 3$ & $1 / 2$ & 1 & 4 & 5 & 6 & 1 & 1 & 1 & 2 & 3 & 4 & 1 & 2 & 3 \\
\hline HİZMET & $1 / 6$ & $1 / 5$ & $1 / 4$ & 2 & 3 & 4 & $1 / 4$ & $1 / 3$ & $1 / 2$ & 1 & 1 & 1 & $1 / 4$ & $1 / 3$ & $1 / 2$ \\
\hline TEKNIKK K. & $1 / 4$ & $1 / 3$ & $1 / 2$ & 4 & 5 & 6 & $1 / 3$ & $1 / 2$ & 1 & 2 & 3 & 4 & 1 & 1 & 1 \\
\hline
\end{tabular}

Öncelik matrisine göre ana kriterlerin ağırlıklarını belirleyebilmek için aşağıdaki adımlar izlenir; Adım 1: Ölçüt i’ ye göre bulanık sentetik mertebenin değeri şu şekilde tanımlanır.

$S_{i}=\sum_{j=1}^{m} M_{g_{i}}^{j} *\left[\sum_{i=1}^{n} \sum_{j=1}^{m} M_{g_{i}}^{j}\right]^{-1}$

$\mathrm{S}_{\mathrm{i}}=\mathrm{i}$. Amacın sentez değeri $\mathrm{M}_{\mathrm{gi}}^{\mathrm{j}}=$ her bir amaca yönelik genişletilmiş değer

Birinci aşamanın sonunda aşağıdaki ifade hesaplanır.

$$
\begin{aligned}
& {\left[\sum_{i=1}^{n} \sum_{j=1}^{m} M_{g_{i}}^{j}\right]^{-1}=\left[\frac{1}{\sum_{i=1}^{n} u_{i}}, \frac{1}{\sum_{i=1}^{n} m_{i}}, \frac{1}{\sum_{i=1}^{n} l_{i}}\right]} \\
& S_{f}=(14,18,22) *(0,01727,0,0217,0,02834)=(0,24173,0,39066,0,62338) \\
& S_{m}=(1,708,1,876,2,167) *(0,01727,0,0217,0,02834)=(0,0295,0,0407,0,06139) \\
& S_{t}=(8,333,11,5,15) *(0,01727,0,0217,0,02834)=(0,14388,0,24959,0,42503)
\end{aligned}
$$


Denizhan B., Yılmaz Yalçıner A., Berber Ş.

$$
\begin{aligned}
& S_{h}=(3,667,4,867,6,25) *(0,01727,0,0217,0,02834)=(0,06331,0,10562,0,1771) \\
& S_{t k}=(7,583,9,83,12,5) *(0,01727,0,0217,0,02834)=(0,13094,0,21341,0,35419)
\end{aligned}
$$

Adım 2: $M_{2}=\left(l_{2}, m_{2}, u_{2}\right) \geq M_{1}=\left(l_{1}, m_{1}, u_{1}\right) \quad$ ifadesinin olabilirlik derecesine göre hesaplanır:

$$
V(M 2 \geq M 1)=\mid \begin{array}{cc}
1 & m_{2} \geq m_{1} \\
0 & l_{1} \geq u_{2} \\
l_{1}-u_{2} & \text { diğer } \\
\frac{\left(m_{2}-u_{2}\right)-\left(m_{1}\right.}{\left.-l_{1}\right)} &
\end{array}
$$

Burada karşılaştırılan iki durum için kesişim noktası bulunuyor. $M_{1} v e M_{2}$ yi kıyaslayabilmek için $V\left(M_{2} \geq M_{1}\right)$ ve $V\left(M_{1} \geq M_{2}\right)$ değerlerinin her ikisi de gerekmektedir. Bu hesaplamalardan elde edilen olasılık değerleri tablo 13'de gösterilmektedir.

\begin{tabular}{|} 
Tablo 13. Kriterlerin olabilirlik değerleri \\
\begin{tabular}{|c|c|c|c|c|c|}
\hline & KALİTE & MALIYET & TESLIMAT & HIZZMET & TEKNIK \\
\hline KALITE & - & 0 & 0,5651 & 0 & 0,3882 \\
\hline MALIYYET & 1 & - & 1 & 1 & 1 \\
\hline TESLIMAT & 1 & 0 & - & 0,18745 & 0,85324 \\
\hline HİZMET & 1 & 0 & 1 & - & \\
\hline TEKNIK K. & 1 & 0 & 1 & 0,29983 & - \\
\hline
\end{tabular}
\end{tabular}

Adım 3: 1. satır diğer tüm satırlarla karşılaştırılır. Bu karşılaştırmalar sonucunda çıkan değerlerin minimumu alınır(d'( $\left.\left(A_{1}\right)\right)$. Aynı şekilde 2. satırda diğer tüm satırlarla karşılaştırılır ve minimumu alınır $\left(d^{\prime}\left(A_{2}\right)\right)$. Bu işlem tüm satırlar için devam ettirilir. Her satır için bulunan minimum değerler birleştirilerek ağırlık vektörü elde edilir.

$$
W^{\prime}=\left(d^{\prime}\left(A_{1}\right), d^{\prime}\left(A_{2}\right), \ldots ., d^{\prime}\left(A_{n}\right)\right)^{T}
$$

Adım 4: Ağırlık vektörü normalize edilir. Burada $W$, bulanık olmayan bir sayıdır.

$$
W=(\quad 0,51195,0,0,28931,0,0,19874)^{\mathrm{T}}
$$

\begin{tabular}{|c|c|c|c|c|c|c|c|c|c|}
\hline \multirow{2}{*}{$\begin{array}{c}\text { KALİTE } \\
\text { K1 }\end{array}$} & \multicolumn{3}{|c|}{ K1 } & \multicolumn{3}{|c|}{ K2 } & \multicolumn{3}{|c|}{ K3 } \\
\hline & 1 & 1 & 1 & 2 & 3 & 4 & 1 & 2 & 3 \\
\hline K2 & $1 / 4$ & $1 / 3$ & $1 / 2$ & 1 & 1 & 1 & $1 / 3$ & $1 / 2$ & 1 \\
\hline K3 & $1 / 3$ & $1 / 2$ & 1 & 1 & 2 & 3 & 1 & 1 & 1 \\
\hline
\end{tabular}

Ana kriterlerin ağırlıkları belirlendikten sonra alt kriterlerin öncelik matrisleri oluşturulur. Oluşturulan matrisler yardımıyla alt kriterlerin ağırlıkları belirlenerek çözüme devam edilir. Tablo 14, 15 ve 16 da kriterlerin karşılaştırılması ve önem ağırlıkları görülmektedir. 
Tablo 15. Teknik Kriterlerin Karșılaștırılması

\begin{tabular}{|c|c|c|c|c|c|c|c|c|c|c|c|c|c|c|c|}
\hline \multirow{2}{*}{$\begin{array}{c}\text { TEKNIK K } \\
\text { TK1 }\end{array}$} & \multicolumn{3}{|c|}{ TK1 } & \multicolumn{3}{|c|}{ TK2 } & \multicolumn{3}{|c|}{ TK3 } & \multicolumn{3}{|c|}{ TK4 } & \multicolumn{3}{|c|}{ TK5 } \\
\hline & 1 & 1 & 1 & $1 / 6$ & $1 / 5$ & $1 / 4$ & $1 / 4$ & $1 / 3$ & $1 / 2$ & $1 / 3$ & $1 / 2$ & 1 & 1 & 2 & 3 \\
\hline TK2 & 4 & 5 & 6 & 1 & 1 & 1 & 1 & 1 & 1 & 2 & 3 & 4 & 6 & 7 & 8 \\
\hline TK3 & 2 & 3 & 4 & 1 & 1 & 1 & 1 & 1 & 1 & 1 & 2 & 3 & 4 & 5 & 6 \\
\hline TK4 & 1 & 2 & 3 & $1 / 4$ & $1 / 3$ & $1 / 2$ & $1 / 3$ & $1 / 2$ & 1 & 1 & 1 & 1 & 4 & 5 & 6 \\
\hline TK5 & $1 / 3$ & $1 / 2$ & 1 & $1 / 8$ & $1 / 7$ & $1 / 6$ & $1 / 6$ & $1 / 5$ & $1 / 4$ & $1 / 6$ & $1 / 5$ & $1 / 4$ & 1 & 1 & 1 \\
\hline
\end{tabular}

$W^{\prime}=(0,1,0,61852,0,30615,0)^{\mathrm{T}}$

$W=(0,0,51957,0,32136,0,15907,0)^{\mathrm{T}}$

Tüm kriterlere göre her bir firma değerlendirilerek çc̈züme devam edilir.

Tablo 16. Teknik kriterler için önem ağırlıkları

\begin{tabular}{ccccccc}
\hline TEKNIK & TK1 & TK2 & TK3 & TK4 & TK5 & ÖNEM \\
KRITERLER & 0 & 0,51957 & 0,32136 & 0,15907 & 0 & AĞIRLIKLARI \\
F1 & 0,31917 & 0,35102 & 0,43057 & 0,68083 & 0,82055 & 0,429047065 \\
F2 & 0,68083 & 0,55833 & 0,56943 & 0,31917 & 0,17945 & 0,523853915 \\
F3 & 0 & 0,09065 & 0 & 0 & 0 & 0,047099021 \\
\hline
\end{tabular}

Ana ve alt kriterlerin ağırlıkları belirlenerek firma karşılaştırmaları yapılmıştır. Tüm verileri bir araya toplayarak en uygun tedarikçinin firma 2 olduğu aşağıdaki tablo 17. ‘de görülebilir.

Tablo 17. Bulanık AHP ile Tedarikçi Seçimi Sonuçları

\begin{tabular}{|c|c|c|c|c|c|c|}
\hline \multicolumn{7}{|c|}{ MAKİNA İMALATI SEKTÖRÜNDE TEDARİKÇİ SEÇIMİ } \\
\hline Ana kriterlerin & KALİTE & MALIYET & TESLIMAT & HİZMET & TEKNİK K. & EN UYGUN \\
\hline ağırlıkları & 0,51195 & 0 & 0,28931 & 0 & 0,19874 & TEDARÍKÇİ \\
\hline F1 & 0,49463 & 0 & 0,35162 & 0,43057 & 0,42905 & 0,440222408 \\
\hline $\mathbf{F} 2$ & 0,45992 & 0 & 0,64838 & 0,56943 & 0,52385 & 0,527148811 \\
\hline F3 & 0,04545 & 1 & 0 & 0 & 0,0471 & 0,032628782 \\
\hline
\end{tabular}

\%52,71 oran ile Firma 2, Bulanık AHP yöntemi ile en uygun tedarikçi seçilmiştir.

\subsection{Bulanık AHP Yöntemi ile Yeşil Tedarikçinin Seçimi}

Önceki adımda Bulanık AHP yöntemi ile yeşil kriterler olmaksızın tedarikçi seçimi uygulanmıştır. $\mathrm{Bu}$ aşamada ise belirlenen yeşil kriterler ilave edilmiştir. İlk olarak en uygun yeşil tedarikçiyi belirleyebilmek için ana kriterler karşılaştırılarak tablo 18. de yer alan öncelik matrisi oluşturulur. 
Denizhan B., Yılmaz Yalçıner A., Berber Ş.

Tablo 18. Ana Kriterlerin Bulanık İkili Karșılaștırma Matrisi Makine İmalatı Sektöründe Yeşil Tedarikçi Seçimi

\begin{tabular}{|c|c|c|c|c|c|c|c|c|c|c|c|c|c|c|c|c|c|c|}
\hline \multicolumn{19}{|c|}{ Makine İmalatı Sektöründe Yeşil Tedarikçi Seçimi } \\
\hline \multirow[b]{3}{*}{ KALITTE } & l & $\mathrm{m}$ & $\mathrm{u}$ & l & $\mathrm{m}$ & u & l & $\mathrm{m}$ & $\mathrm{u}$ & l & $\mathrm{m}$ & $\mathrm{u}$ & l & $\mathrm{m}$ & $\mathrm{u}$ & 1 & $\mathrm{~m}$ & $\mathrm{u}$ \\
\hline & \multicolumn{3}{|c|}{ KALITTE } & \multicolumn{3}{|c|}{ MALIYET } & \multicolumn{3}{|c|}{ TESLİMAT } & \multicolumn{3}{|c|}{ HİZMET } & \multicolumn{3}{|c|}{ TEKNIK K. } & \multicolumn{3}{|c|}{ YEŞIL K. } \\
\hline & 1 & 1 & 1 & 6 & 7 & 8 & 1 & 2 & 3 & 4 & 5 & 6 & 2 & 3 & 4 & 1 & 1 & 1 \\
\hline MALIYET & $1 / 8$ & $1 / 7$ & $1 / 6$ & 1 & 1 & 1 & $1 / 6$ & $1 / 5$ & $1 / 4$ & $1 / 4$ & $1 / 3$ & $1 / 2$ & $1 / 6$ & $1 / 5$ & $1 / 4$ & $1 / 9$ & $1 / 9$ & $1 / 8$ \\
\hline TESLİMAT & $1 / 3$ & $1 / 2$ & 1 & 4 & 5 & 6 & 1 & 1 & 1 & 2 & 3 & 4 & 1 & 2 & 3 & $1 / 4$ & $1 / 3$ & $1 / 2$ \\
\hline HİZMET & $1 / 6$ & $1 / 5$ & $1 / 4$ & 2 & 3 & 4 & $1 / 4$ & $1 / 3$ & $1 / 2$ & 1 & 1 & 1 & $1 / 4$ & $1 / 3$ & $1 / 2$ & $1 / 8$ & $1 / 7$ & $1 / 6$ \\
\hline TEKNIK K. & $1 / 4$ & $1 / 3$ & $1 / 2$ & 4 & 5 & 6 & $1 / 3$ & $1 / 2$ & 1 & 2 & 3 & 4 & 1 & 1 & 1 & $1 / 6$ & $1 / 5$ & $1 / 4$ \\
\hline YEŞIL K. & 1 & 1 & 1 & 8 & 9 & 9 & 2 & 3 & 4 & 6 & 7 & 8 & 4 & 5 & 6 & 1 & 1 & 1 \\
\hline
\end{tabular}

Verilen öncelik matrisine göre ana kriterlerin ağırlıkları belirlenir. Tablo 19. da yer alan olabilirlik değerleri belirlenir.

\begin{tabular}{ccccccc}
\multicolumn{7}{c}{ Tablo 19. Kriterlerin olabilirlik değerleri } \\
\hline KALiTE & KALİTE & MALiYET & TESLIMAT & HİZMET & TEKNiK K. & YEŞíL K. \\
MALIYET & - & 0 & 0,49299 & 0 & 0,28204 & 1 \\
TESLIMAT & 1 & - & 1 & 1 & 1 & 1 \\
HİZMET & 1 & 0 & - & 0,11811 & 0,83099 & 1 \\
TEKNIKK K. & 1 & 0 & 1 & - & 1 & 1 \\
YEŞiL K. & 0,60124 & 0 & 0,07545 & 0 & 0 & 1 \\
\hline
\end{tabular}

$$
\begin{aligned}
& W^{\prime}=(0,60124, \quad 0, \quad 0,07545, \quad 0,0,1)^{\mathrm{T}} \\
& W=(0,35859,0,0,045,0,0,0,59641)^{\mathrm{T}}
\end{aligned}
$$

Ana kriterlerin ağırlıkları belirlendikten sonra alt kriterlerin öncelik matrisleri oluşturulur. Oluşturulan matrisler yardımıyla alt kriterlerin ağırlıkları belirlenerek çözüme devam edilir. Yeşil kriterler dışındaki alt kriterlerin öncelik matrisleri ve ağırlıkları, bir önceki çözümde belirtildiği gibidir. Yeşil kriterlerin öncelik matrisini oluşturarak ağırlıkları belirlenmiştir. Tablo 20 de yer alan karşılaştırmalı yeşil kriterler oluşturulmuştur.

\begin{tabular}{|c|c|c|c|c|c|c|c|c|c|c|c|c|c|c|c|}
\hline \multirow{2}{*}{$\begin{array}{c}\text { YEşİL K. } \\
\text { Y1 }\end{array}$} & \multicolumn{3}{|c|}{ Y1 } & \multicolumn{3}{|c|}{ Y2 } & \multicolumn{3}{|c|}{ Y3 } & \multicolumn{3}{|c|}{ Y4 } & \multicolumn{3}{|c|}{ Y5 } \\
\hline & 1 & 1 & 1 & 1 & 1 & 1 & 4 & 5 & 6 & 2 & 3 & 4 & 6 & 7 & 8 \\
\hline Y2 & 1 & 1 & 1 & 1 & 1 & 1 & 2 & 3 & 4 & 2 & 3 & 4 & 6 & 7 & 8 \\
\hline Y3 & $1 / 6$ & $1 / 5$ & $1 / 4$ & $1 / 4$ & $1 / 3$ & $1 / 2$ & 1 & 1 & 1 & $1 / 4$ & $1 / 3$ & $1 / 2$ & 2 & 3 & 4 \\
\hline Y4 & $1 / 4$ & $1 / 3$ & $1 / 2$ & $1 / 4$ & $1 / 3$ & $1 / 2$ & 2 & 3 & 4 & 1 & 1 & 1 & 2 & 3 & 4 \\
\hline Y5 & $1 / 8$ & $1 / 7$ & $1 / 6$ & $1 / 8$ & $1 / 7$ & $1 / 6$ & $1 / 4$ & $1 / 3$ & $1 / 2$ & $1 / 4$ & $1 / 3$ & $1 / 2$ & 1 & 1 & 1 \\
\hline
\end{tabular}

Tablo 20. Yeşil Kriterlerin Karşılaştırılması

$$
\begin{aligned}
& W^{\top}=\left(\begin{array}{l}
1,0,84807, \quad 0,0,10461,0 \\
{ }^{\mathrm{T}}
\end{array}\right. \\
& W=\left(\begin{array}{ll}
0,51212,0,43431,0,0,05357,0 & 0
\end{array}\right)^{\mathrm{T}}
\end{aligned}
$$

Tüm kriterlere göre her bir firma değerlendirilerek çözüme devam edilir. Yeşil kriterler dışındaki kriterlerin firmalara göre değerlendirilme matrisleri, bir önceki çözümde verilmiştir. Yeşil kriterler de firmalara göre değerlendirilerek çözüme devam edilir. 
Nevşehir Bilim ve Teknoloji Dergisi Cilt 6(1) 63-78 2017

\begin{tabular}{ccccccc}
\multicolumn{7}{c}{ Tablo 21. Yeșil kriterler için önem ağırlıkları } \\
\hline YEŞiL & Y1 & Y2 & Y3 & Y4 & Y5 & ÖNEM \\
KRITERLER & 0,51212 & 0,43431 & 0 & 0,05357 & 0 & AĞIRLIKLARI \\
F1 & 0,56279 & 0,68083 & 0,43721 & 0,5 & 0,43057 & 0,610692292 \\
F2 & 0,43721 & 0,31917 & 0,56279 & 0,5 & 0,56943 & 0,389307708 \\
F3 & 0 & 0 & 0 & 0 & 0 & 0 \\
\hline
\end{tabular}

Ana ve alt kriterlerin ağırlıkları belirlenerek firma karşılaştırmaları yapılmıştır. Tüm verileri bir araya toplayarak en uygun yeşil tedarikçinin firma \%55,74 oran ile Firma 1, en uygun yeşil tedarikçi seçilmiştir. Tablo 22. de görülmektedir.

Tablo 22. Bulanık AHP ile Yeşil Tedarikçi Seçimi Sonuçları

\begin{tabular}{|c|c|c|c|c|c|c|c|}
\hline \multicolumn{8}{|c|}{ MAKİNA İMALATI SEKTÖRÜNDE YEŞİL TEDARİKÇİ SEÇİİ } \\
\hline Ana kriterlerin & Kalite & Maliyet & Teslimat & Hizmet & Teknik k. & Yeşil k. & EN YEŞILL \\
\hline ağırlıkları & 0,35859 & 0 & 0,045 & 0 & 0 & 0,59641 & TEDARİKÇİ \\
\hline $\mathrm{F} 1$ & 0,49463 & 0 & 0,35162 & 0,43057 & 0,42905 & 0,61069 & 0,557413895 \\
\hline $\mathrm{F} 2$ & 0,45992 & 0 & 0,64838 & 0,56943 & 0,52385 & 0,38931 & 0,42628819 \\
\hline F3 & 0,04545 & 1 & 0 & 0 & 0,0471 & 0 & 0,016297916 \\
\hline
\end{tabular}

Yeşil kriterlerin dahil edilerek ve dahil edilmeden yapılan tedarikçi seçimi sonuçları tablo 23 de görüldüğü gibi değişkenlik göstermektedir.

Tablo 23: Çözüm yöntemleri ve sonuçları

\begin{tabular}{cccc}
\hline \multirow{2}{*}{ Çözüm Yöntemi } & \multicolumn{2}{c}{ Sonuç } & \\
& & Oran & Firma \\
\multirow{2}{*}{ AHP } & En uygun tedarikçi & $42,80 \%$ & Firma 2 \\
& En yeşil tedarikçi & $44,00 \%$ & Firma 1 \\
& En uygun tedarikçi & $52,71 \%$ & Firma 2 \\
BULANIK AHP & En yeşil tedarikçi & $55,74 \%$ & Firma 1 \\
\hline
\end{tabular}

\section{Sonuç ve Öneriler}

Yaşamsal kaynakların hızla tükendiği günümüzde yeşil tedarik zincirinin önemi de artmakta ve geleneksel tedarik zincirlerinin yerini almaktadır. Yeşil tedarik zinciri bütünleşmesi, işlemlerde çevresel yönetime fayda sağlayabilir. Bu çalışmada firmalardan yeşil kriterlerin önem sıralamasının yapılması istenildiğinde; yeşil tasarım yeteneği, üretim sürecinde yeşil malzeme kullanımı, yeşil pazar payı ve üst yönetim desteği gibi seçeneklerin ilk sıralarda yer almadığı görülmektedir. Yeşil pazar payının düşük olması ve üst yönetim desteğinin olmaması, yeşil üretime ve yeşil ürünlere geçiş sürecini yavaşlatmaktadır. AHP ve Bulanık AHP yöntemleri ile en uygun ve en yeşil tedarikçilerin belirlendiği dört sonuç elde edilmiştir. Her iki çözüm yönteminde de yeşil kriterler dâhil edilmeden yapılan en uygun tedarikçi seçiminde Firma 2 ön plana çıkarken, yeşil kriterlerin dâhil edilmesi ile en yeşil tedarikçinin Firma 1 olduğu görülmektedir. Sonuçların tutarlılığını ölçmek için AHP ve BAHP yöntemleri birlikte kullanılmıştır. Bulanık AHP ve AHP ile yapılan uygulamada sıralamaların değişmediği, fakat Bulanık AHP'de yüksek önem derecesine sahip kriterlerin ağırlığının daha da arttığı, düşük önem derecesine sahip 
kriterlerin de ağırlı̆ı̆ının azaldığı görülmektedir. Böylece Bulanık AHP'nin iyi olanı daha yukarı çekerken, kötü olanı da daha aşağı iterek sonucu belirginleştirdiği sonucu çıkarılabilmektedir.

Firmaların birlikte çalıştığı tedarikçilerinden yalnız birinin çevreye daha duyarlı ürün/hizmet sunacağı ancak maliyetleri biraz arttırdığı belirtmiştir. İlişkinin devam etmesi maliyetlerin ne ölçüde arttırıldığına bağlı, cevabı ön plana çıkmaktadır. Bu ise şirketlerin karar aşamasında çevreye ve insan sağlığına etkilerinden ziyade maliyetleri daha ön planda tuttuğunu göstermektedir. Firmaların daha önce çevreci tedarikçilerle pek karşılaşmadıkları, tedarikçilerle ilişki süreçlerini çevreci kriterlerin çok etkilemediği görülmektedir. Müşterilerin firmaları tercih etme sebepleri sorulduğunda; kalite ve fiyat ön plana çıkmaktadır. Müşterilerden firmalara çevreci olmaları konusunda pek baskı gelmediği, yabancı müşterilerin yerli müşterilerden çevre konusunda daha duyarlı olduğu görülmektedir. Firmaları çevreci olmaya iten temel sebeplerde, devlet baskısı ve rakip baskısı ön plana çıkmaktadır. Çevreci olmakla ilgili görüşleri sorulduğunda; çevreci olmanın firma imajını güçlendireceği fakat çeşitli maliyetleri de beraberinde getireceği, yeşil pazar payının düşük olması sebebiyle rekabet gücünde pek etkili olmayacağı, buna rağmen devlet yaptırımları ve rakip baskıları sonucunda çevreci çalışmaların gündemde olduğu ön plana çıkmaktadır.

Yeşil satın alma kararları; yeniden kullanılabilen veya geri dönüştürülmüş malzemelerin satın alınması faaliyetlerini içermektedir. Bu noktada önemli olan, doğal kaynak tasarrufunun sağlanması ve çevreye en az zararın verilmesidir. Doğal kaynakların tasarrufu ise hammadde tedarikçilerinin mümkün olduğunca geri dönüşüm yapan tedarikçilerle değiştirilmesi ile mümkündür. Ayrıca çevre ile ilgili problemleri çözebilmek ve karşlıklı yararlar sağlayacak sonuçlar yaratmak için stratejik olarak işletmelerin, tedarikçileriyle hatta tedarikçilerin tedarikçileriyle de ortak bir çalışma yürütmeleri gerekir. Başka bir deyişle, tüm tedarik zincirinin çevresel performansının geliştirilmesi için tedarikçilerin çevre yönetimine entegre edilmeleri gerekir. Tüm bu nedenler, yeşil satın alma faaliyetinde en önemli unsurun tedarikçi seçimi olduğunu göstermektedir. Dolayısıyla bu noktada ortaya çıkan en büyük problem, hangi tedarikçinin işletmenin dahili çevre yönetim sistemine entegre edileceğidir. Bunun içinse tedarikçilerin çevre kriterlerine göre değerlendirilmesi gerekmektedir. Müşterilerin büyüklüğü tedarikçilerin çevresel uygulamaları benimsemesi için çok önemlidir.

Bunun yanı sıra, üretim yapan işletmeler için yeşil tedarik zinciri sürecinin yeniden tasarımı gerekebilir. Mevcut tesis, makine ve sistemler yeni üretim ve süreç için uygun olmayabilir. Sadece yatırım açısından değil yeni sistemlerin kurulması, tesise uyarlanması, yeni ekipmanların kurulumu ya da ayarlanması ve yeni sistemin kurulumu uzun zaman almaktadır. Aynı zamanda işletmeler yeni bir çevreye uyum sağlayacak eleman da yetiştirmelidirler. Diğer taraftan, tedarikçi değerleme ve seçim kararları rutin olduğundan çok az işletme bu kararlara çevresel işbirliği konuları için yaklaşım ve yöntem geliştirebilirler. Her tedarikçi, yeşil tedarik zincirini uygulama yeteneğine sahip değildir. Birçok tedarikçide, özellikle küçük olanlarda sermaye ve kaynak eksikliği bulunmaktadır. Bu tedarikçiler yeterli bilgi, kaynak ve deneyime sahip olmadıkları için yeşil tedarik zinciri yönetiminin uygulamasına isteksiz olabilmektedirler. Yeşil tedarik zinciri işletmeleri, tedarikçileri için eğitim ve işyeri sağlayabilmelidirler.

Yapılan araştırmalarda, geçmişte yeşil tedarik zinciri yönetim uygulamalarının anahtar faktörü olarak tedarikçileri tanımlayan araştırmaların yetersiz olduğu görülmektedir. Tedarikçilerin, çevre projelerini uygulamada fikir sağlamaya yardım edebilecekleri tavsiye edilmektedir. Ancak tedarikçiler 
genellikle doğrudan rol oynamamaktadırlar. Geçmiş araştırmaların yetersizliği, bu faktör henüz araştırılmamış olduğu için ya da tedarikçilerin çevre tedarik uygulamaları üzerindeki etkisinin yeterince algılanamadığı da düşünülmektedir. Yapılan literatür araştırması sonucunda, yeşil tedarik zinciri uygulamaları konusunda ülkemizdeki çalışmaların sayısı da kısıtlı olduğundan, işletmelerin bu konudaki faaliyetleri, karşılaştıkları sorunlar, yurt dışında yapılan uygulamalar ile yerel uygulamalar arasındaki farklılıkların belirlenmesi de güç olmaktadır. Bununla birlikte genel olarak yöneticilerin, yeşil tedarikçi seçiminde; kalite performansı, çevre politikası ve bilinci, çevresel etkinlikleri ve başarılarındaki belgeleri, ürünün güvenilirliği ve doğruluğu, ambalajlama ve diğer konulardaki iddiaları gibi ilkeleri göz önünde bulundurmaları toplumsal çevre bilinci açısından da önem kazanmaktadır.

\section{Kaynaklar}

[1] Andrea Genovese, S.C. Lenny Koh, Guiseppe Bruno, Paolo Bruno, “Green Supplier Selection: a literature Review and Critical Perspective”, 8th International Conference on Supply Chain Management and Information, 2010.

[2] CAPİTAL, "Yeşil Tedarikçi Dönemi”, http://www.capital.com.tr/green-business/yesil-tedarikcidonemi-haberdetay-10617 2014, (Erişim tarihi: 09/03/2016).

[3] Çelikçapa, F.O., “Üretim Yönetimi ve Teknikleri”, Alfa Basım Yayım, Bursa, 2007.

[4] De Boer, L., Labro, E., Morlacchi, P., “A Review of Methods Supplier Selection” European Journal of Purchasing\&Supply Management,7:75-89, 2001.

[5] Deshmukh, A.J., Vasudevan, H. "Emerging Supplier Selection Criteria in the Context of Traditional vs Green Supply Chain Management” International Journal of Managing Value and Supply Chains, 5 (1):19-33, 2014.

[6] Görener, A., Toker, K., Uluçay, K., “Application of Combined SWOT and AHP: A Case Study for a Manufacturing Firm”, 8th International Strategic Management Conference, Procedia Social and Behavioral Sciences, 58, 1525 - 1534, 2012.

[7] Green, K., Morton, B., New, S., “Green Purchasing and Supply Policies: Do They Improve Companies Environmental Performance?” Supply Chain Management, 3 (2):89-95, 1998.

[8] Güner, S., “Kobi’lerde Yeşil Tedarik Zinciri Algılaması: Sakarya Bölgesi Uygulaması”, Yüksek Lisans Tezi, Sakarya Üniversitesi Fen Bilimleri Enstitüsü Endüstri Mühendisliği Anabilim Dalı, Sakarya, 2010.

[9] Hamner, B., Del Rosario, T., "Green Purchasing: A Channel for Improving the Environmental Performance of SMEs”, Globalisation and the Environment: Perspectives from OECD and Dynamic Non-Member Economies, OECD Publishing, 1998.

[10] Kargın, M., "Bulanık Analitik Hiyerarşi Süreci ve İdeal Çözüme Yakınlığa Göre Sıralama Yapma Yöntemleri ile Tekstil Sektöründe Finansal Performans Ölçümü”, Celal Bayar Üniversitesi Sosyal Bilimler Enstitüsü Dergisi, 8(1), 195-216, 2010.

[11] Kuruüzüm, A., Atsan, N., “Analitik Hiyerarşi Yöntemi ve İşletmecilik Alanındaki Uygulamaları”, Akdeniz Üniversitesi İktisadi ve İdari Bilimler Fakültesi Dergisi, 1(1), 83-105, 2001. 
[12] Lee, A.H.I., "A Fuzzy Supplier Selection Model with the Consideration of Benefits, Opportunities, Costs and Risks”, Expert Systems with Applications, 36, 2879-2893, 2009.

[13] Nassimbeni, G., (2003). "Local Manufacturing Systems and Global Economy: Are They Compatible? The Case of the Italian Eyewear District”, Journal of Operations Management, 21:151-171, 2003. (Erişim tarihi: 12/11/2016)

[14] Nielsen, I.E., Banaeian, N., Golinska, P., Mobli, H., Omid, M., "Green Supplier Selection Criteria: From a Literature Review to a Flexible Framework for Determination of Suitable Criteria”, Springer International Publishing, 2014.

[15] Özdemir, M.S., "Bir İşletmede Analitik Hiyerarşi Süreci Kullanılarak Performans Değerleme Sistemi Tasarımı”, Endüstri Mühendisliği Dergisi, 13(2), 2-11, 2002.

[16] Özyörük, B., Özcan, E.C., “Analitik Hiyerarşi Sürecinin Tedarikçi Seçiminde Uygulanması: Otomotiv Sektöründen Bir Örnek”, Süleyman Demirel Üniversitesi IIBBF Dergisi, 13 (1):133144, 2005.

[17] Saaty R.W., "The Analytic Hierarchy process-what it is and how it is used”, Mathematical Modelling, Vol 9, Issue 3-5, 1987, pp 161-176.

[18] Supçiller, A.A., Çapraz, O., "AHP TOPSIS Yöntemine Dayalı Tedarikçi Seçimi Uygulaması”, İstanbul Üniversitesi İktisat Fakültesi Ekonometri ve İstatistik Dergisi, 13:1-22, 2011.

[19] Şen, Z., “Bulanık Mantık İlkeleri ve Modelleme”, Su Vakfi Yayınları, 23, İstanbul, 2009.

[20] Vargas, L.G., “An Overview of the Analytic Hierarchy Process and Its Applications”, European Journal of Operational Research, 48, 2-8, 1990.

[21] Xia, W., Wu, Z., "Supplier Selection with Multiple Criteria in Volume Discount Environments”, Omega, The International Journal of Management Science, 35, 494 -504, 2007.

[22] Narges Banaeian, Hossein Mobli Behnam Fahimnia, Izabela Ewa Nielsen' Mahmoud Omid, "Green supplier selection using fuzzy group decision making methods: A case study from the agri-food industry”, Computers \& Operations Research, Available online 4 March 2016.

[23] Zadeh, Lotfi, 1965. "Fuzzy sets and systems". In: Fox J, editor. System Theory. Brooklyn, NY: Polytechnic Press, 1965. 